\section{BRADSHAW LECTURE}

\author{
or
}

\section{NERVE-STRETCHING FOR THE RELIEF OR CURE OF PAIN.}

Delivered at the Royal College of Surgeons of England, December 6th, 1883.

BY JOHN MARSHALL, F.R.C.S., F.R.S., President of the College.

Dr. William Woods Bradshaw, who was a physician practising at Andover and then at Reading, was M.D. of the University of Erlangen, and he also held other titles of that University. He was M.A: of the University of Oxford; he was a Member of the Royal Callege of Physicians, London, and Fellow of this College; he was, therefore, a man who was not altogether undistinguished in our profession, and one who held a high position in the county in which he resided. He contributed a few papers to the medical journals, and he also indulged himself in writing articles on matters of general interest, under the signature of Beta. He died seventeen years ayo, in the month of August, and fourteen years afterwards his widow left $£ 1,000$ to the College of Physicians, and another $£ 1,000$ to this College, in order to establish perpetual lectureships. This lectureship has been held only once before this day, by Sir James Paget; and as my immediate predecessor chose for his subject some "new" forms of disease, soI have chosen for the lectur e on this occasion the subject of what may be termed a "new" operation, for it is only within the last eleven or twelve years that this operation has been introduced, and has been used gradually more and more extensively for the "relief or the cure of pain." It has also been applied to a great number of spasmodic diseases of the nervous system; but it is in relation to its effects in relieving "pain" that I chiefly wish now to direct your attention to this particular operation of " nerve-stretching." The first thing I have to say concerning nerve-stretching is, that you must understand by it not the mere drawing out of a nerve, so that you may see it lifted from its bed in the body, but a palpable stretching. And this opens up the question, Can a nerve be stretched? Now, nerves are extensible to a certain degree, but to a much slighter degree than you would imagine. There is a Table here showing the degree of extensibility of nerves, and you will find that the results are, after all, not very great. One observer says that a nerve may be stretched to one twenty-fourth of its length; another observer makes out a larger amount of stretching; and another a still larger amount.

Extensibility of Nerves.-Human Nerves after Death.

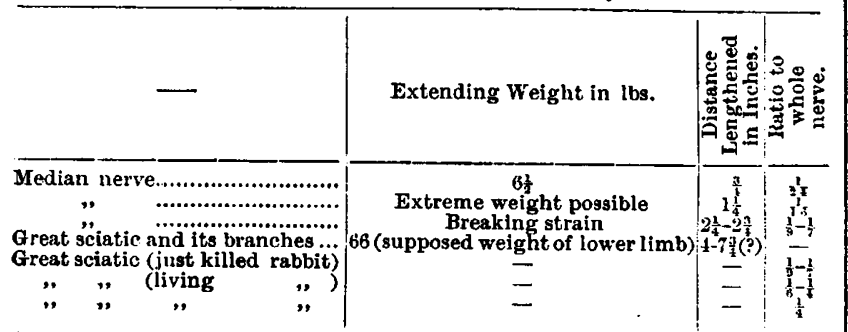

Human Nerre.
(after death)

Rabbit (living)

$$
\text { Elasticity of Nerres. }
$$$$
\text { .......... }
$$

\section{extended}

(one experiment.) retracted

to ${ }^{3}$ wholly
But, after all, one is surprised at the small amount of stretching of which a nerve is capable. The following simple experiment will show you that a nerve is not so very extensible, though it is extensible. Here is a piece of tendon, and here a piece of nerve; the same weight is applied to the same length of tendon, and the same length of nerve; and you will see how very inextensible the tendon is, and how the nerve has only given way a very small degree beyond the tendon. You must remember, however, that the weights em. ployed in the cases mentioned in the table were considerable, some of them as much as 20,30, and even $80 \mathrm{lbs}$. Here, however, we have only a $4 \mathrm{lb}$. weight. No doubt, with a greater weight on a perfectly fresh piece of nerve, the nerve would extend still more than this; at the same time, the amount of extensibility of nerve is certainly comparatively slight. It is not nearly so extensible as an artery, but it is somewhat more extensible than a tendon. It has been noticed, with regard to this extension, that the nerves nearer to the spinal cord are rather more extensible than those at a distance. This may be owing to the relatively less thickness of the sheath; the distant nerves are smaller, but they are probably better protected.

It has been observed that the nerves of the upper limb are more extensible than those of the lower limb, probably for the same reason-that the nerves of the lower limb are better protected by sheaths; for we must recognise that it is the sheath that bears the strain when you pull upon a nerve. It has also been noticed that a long piece of nerve will stretch a great deal more, relatively, than a short one, and this is only in harmony with what takes place in common extensible tissues. If you take two pieces of elastic tube, one twice the length of the other, and load them with the same weight, you will find that the longer piece will stretch, relatively, more than the shorter one. This piece, for example, has stretched about two inches with $1 \mathrm{lb}$. weight, and this other will stretch nearly five inches; so, also, the longer the nerve is, the greater is its elasticity, the greater amount of stretching it will bear.

The next point we come to is the recoil of the nerve. After you have stretched a nerve, does it recoil ? We find that observers have proved that it does recoil. According to one observer, the elasticity was so great that, although it had been stretched of its length, it recoiled towithin $\frac{1}{50}$ of its original length. This shows the recovering power in the sheath of the nerve. Observe, that in the living animal the extensibility of a nerve is greater, and so is its elasticity. A living nerve will stretch a great deal more, with all itg tissues in a fine healthy condition-the sheath flexible, its elements mobile over each other-than the dead nerve; so, on the other hand, it will recoil more effectually; its elasticity is greater, its power of recovery greater. This is just what we might expect.

Passing on to other considerations as to the effect of this pulling upon a nerve, the next point is, how much weight will a nerve bear? Now, it is very remarkable that nerves will bear such an extraordinary weight before they break. In the Table before you, you Colesion of Nerves.-Breaking Strain in Pounds.

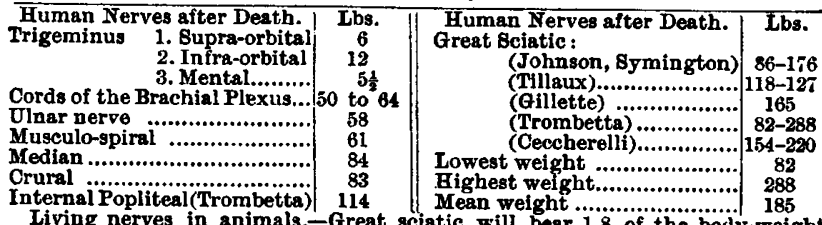
Living nerves in animals. - Great sciatic will bear 1.8 of the body-weight (Btintzing).

Average weight of human body is $150 \mathrm{lbs} . ; 1.8$ of $150 \mathrm{lbs} .=83.3 \mathrm{lbs}$.

The normal function of healthy sciatic nerve completely restored, even after the nerve has been stretched with a force equal to a little more than half the body-weight. (Stintzing.)

Safe strain for healthy sciatic (man) $60 \mathrm{lbs}$.

will see a list of the breaking-weights of some of the smaller nerres of the body, varying from $6 \mathrm{lbs}$. in the case of one of the branches of the trigeminus, to $12 \mathrm{lbs}$. in another branch, increasing in weight until you get to the brachial plexus, the median, the crural, and so on, gradually, with the size of the nerve. However, for a moment, let us give special attention to the breaking-weight of the sciatic nerve. This has been tested by Symington, by Tillaux, by Gillette, by Trombetta, and others, and they differ most extraordinarily. The weights vary from $82 \mathrm{lbs}$. up to $280 \mathrm{lbs}$. This discrepancy, of course, must be accounted for, and can be accounted for on various grounds. There is no doubt they examined the nerves of persons of different height and conformation, and of persons, probably, who were not in identical conditions of health ; some of the nerves might were been themselves diseased; then, again, the nerves were examined at different periods after death, in different climates-some in hot and some in cold climates, when, no doubt, the effect of post morten changes might fully account for differences in the results. As the mean result of these various experiments, you find that $180 \mathrm{lbs}$. is the weight that the sciatic nerve will bear. You can understand, therefore, that when I just now put only a $4 \mathrm{lb}$. weight upon a nerve of this size, I was far within the power that is required in order fully to stretch the nerve.

We will now pass from this Table (to which I shall have to return immediately) with only one further remark: that, as I contrasted the effects on the dead and the living nerves just now, so here it is 
shown, after Stintzing (to whose, name I shall have again to refer), that, whereas the sciatic nerve of a dead animal broke with half the woight of its own body, that weight being about ten pounds, another living sciatic nerve bore 1.8 of the body-weight: "This again shows a great difference in the power that there is in the living as compared with the dead nerve to resist force. But still more interesting results are displayed when we examine the effect of stretching on the structure of a nerve. Here I might express the general result in the form of a truism.' We may say that experiment has shown that every constituent of the nerve is more or less modified, altered, or changed, by a force applied to it, in proportion to the forceitself. As I have said, this is a truism; but it is valuable, as throwing sort of mantle of reconciliation over the various observations and facts that have been accumulated on this subject during the last eleven or twelve years. No one who has not perused the literature of this subject can understand how extremely varied the facts are that have been recorded upon it. If, however, we recollect that the particular results vary according to the force nsed, we shall find that we may pass in a very general way over the effects that have been produced.

Before nerve-stretching came into vogue as an operation, Haber and Harless examined the effects of stretching nerves. They pointed out the tension of the sheath, the elongation of the fascicul and fibres, and the compression of these within the tightened sheath. Valentin went further, and showed that the small individual tubules of the nerve were elongated and narrowed in diameter. Vogt added to these observations-chiefly, however, by confirming them. Gen noticed remarkable constrictions formed on the tubules of the nerve, to which I shall refer. Quinquand discovered segmentation in the so-called meilullary sheath of the nerve. Schleich observed that the segments were at last broken; and that here and there you sat the axis-cylinder, as it is called, passing through them.

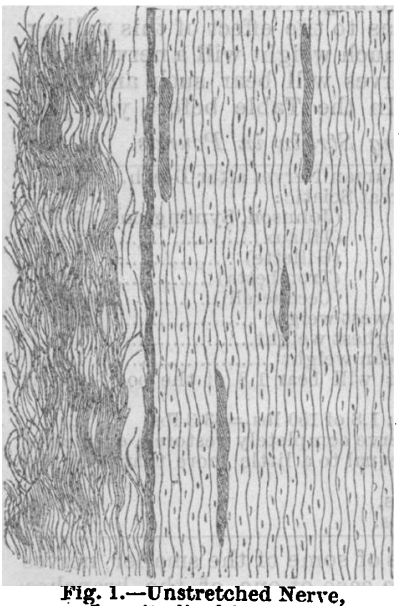

ig. 1.- Unstretched Ner
Longitudinal Bection.

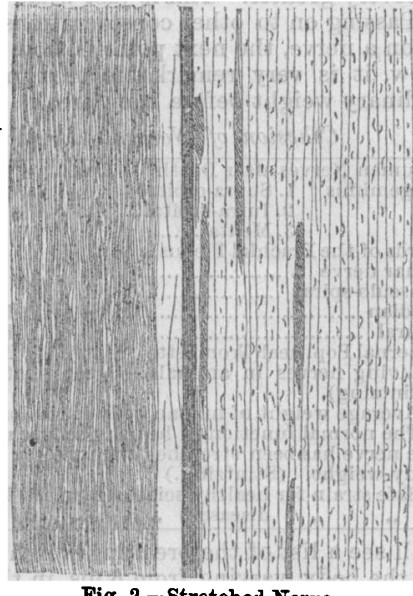

Fig. 2.-Stretched Nerve, Longitudinal Sectioul.

Here, then, we have a series of observations upon the effects of stretching upon the nerve-tubules. At my. instigation, Mr. Horsley has made many interesting observations, some of which certainly seem to throw additional light upon this subject, and for which think, his ingenuity must be praised. He has made sections for me of an ordinary unstretched neive, and of a stretched nerve; and on the diagrams here exhibited, drawn from his specimens under the microscope, we can trace much more effectually than I can do by mere description what these various observers have seen as actual changes in the several constituents of a nerve. In the sheath or epineurium, which covers the nerve, you will find, in the unstretched specimen (Fig. 1), that the fibres are beautifully wavy, like the ordinary fibres of fibrous tissue. You find also that the tubules are, more or less; loose in their sheath, and that even the lubules are, more membrane lying between the epineurium and the tubules, also presents thiskind of wavy contour in the unstretched state. Blood-vessels are seen at intervals lying in this position. Contrasted with this specimen is one from the same median nerve stretched by a weight of twenty-eight pounds, far. within its breaking strain, which would be above sixty pounds. Here you find (Fig. 2) that the instead of being wavy, are in perfectly straight lines, stretched out as tight as they can be ; that the perineurium is perfectly straight, and that the tabules are somewhat narrowed, and also stretched to an extraordinary degree. In a transierse section of the unstretched nerve (Fig. 3); we see the spaces in which the fasciculi of the nerve-fibres lie, the smaller bundles being represented as combining into a larger one, the individual tubules of the nerves being represented in the centre, constituting each fasciculus. In this condition the perineurium is loose, the channels or tubes in which the nerve-fasciculi lie are more or less open, and there is a space between the fasciculus and the perineurium, that space being most likely a lymphatic space, occupied during lifetime with lymphatic fluid. The vessels are drawn of a largish size, but in this section (Fig. 4) we see, irrespectively of the changes that may be supposed to take place in the smaller vessels, a complete alteration. You find the epineurium or sheath again tightened in its tissue, and marked with straight rigid lines, as if the whole texture was pulled out tight, and cut in a sort of hard, solid block. You find the fascicnli compressed, and the lymphatic space between the actual covering of these bundles obliterated, indicating, as it would appear, the compression of the bundles. This is the compression which, no doubt, Haber and Harless observed many years ago; but they did not show it in the vory decided way in which Mr. Horsley has done.

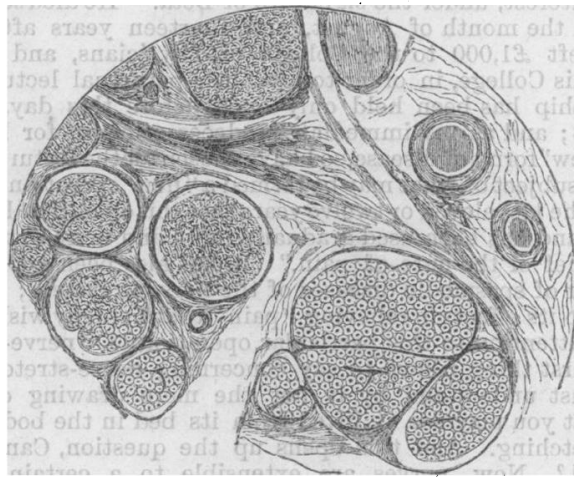

Fig. 3.-Unstretcled Nerve, Transverse Section.

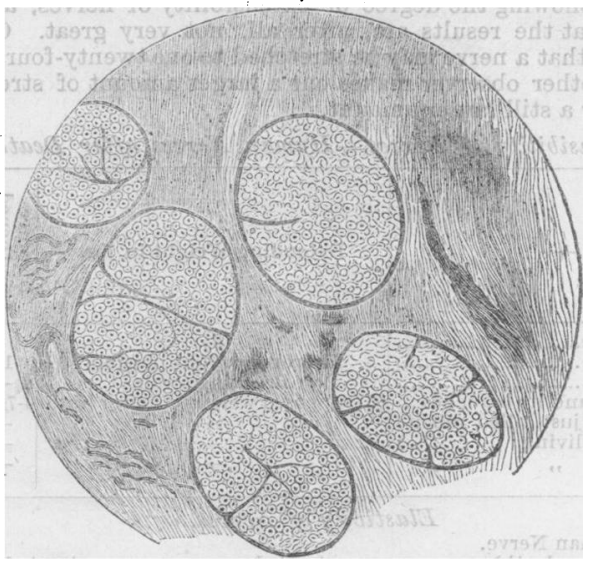

Tig. 4.-Btretched Nerve, Longitudinal Bection.

Now let us consider what other changes must take place in the nerve-tubules. Here is the drawing of a nerve-tubule, with one of its annular notches in the natural state, and here is the nucleus of a nerve-tubule. The outer sheath of Schwann is also represented. The black part represents the soft medullary sheath, the lighter part the axis-cylinder or axis-fibre. It had been observed by Leuterman, that the medullary sheath, after a certain time, broke into these curious segments, not large segments between the annular constrictions of the tubule, but the medullary substance frequently segmented in this curious way. It is evidently not an accidental occurrence. It might be a crystallisation, or a solidification, or coagulation, but at all events it presents these curious segmented appearances. This was published by Leuterman but it was discovered, quite independently, by Mr. Horsley, and for this reason I 
wished him to have this diagram here to-day. Besides the segmentation of the medullary matter, which seems to be natural, other appearances, which have been noticed even in healthy unstretched nerves, are these numerous constrictions which probably really occur opposite the segmented parts of the medullary sheath. This appearance has also been observed by Mr. Horsley, quite independently of the earlier observations of the author I am quoting. In a stretched nerve the segmentation assumes not quite its regular character, but a more irregular character. This, however, is a regular segmentation, supposing it to be carried a little further than you see above. Below, is the effect upon a stretched nerve where those segments are broken up. The medullary sheath lies in irregular masses, whilst most observers agree that the tubular part of the nerve is not broken, or that it is very rarely broken, and that the axis-cylinder is still more rarely torn across. It is only by Marcus and Weit that the observation has been made of the breaking of the axis-cylinder-fibre, but rupture of the fine hyaline sheath has been noticed by other observers; so that we find, when we examine the minute changes which take place, that the natural segmentation seems to give way to an abnormal or irregular breaking up of the medullary sheath; that sometimes the tubuli break, and that still more rarely the axis-cylinder gives way. These observations have been made, not only upon dead nerve, that is to say, a nerve that has been dead some time, but also upon the nerves of animals that have been recently killed. Here, then, we get a series of very remarkable changes, demonstrated to be produced upon a nerve by stretching.

If we push this a little further, and inquire what takes place in a living nerve, we find that these anatomical changes are followed by degenerations; and these degenerations may be spoken of just as well under the description of the anatomy of the part, as under the account of the physiological changes which take place. Degenerations naturally follow in all these tissues. The sheath becomes infiltrated and hyperæmic, charged with little ecchymoses, and larger hæmorrhages; the vessels become compressed or twisted; and the Irmphatics must undergo a similar compression. Then, with regard to the tubules themselves, degenerative changes are rapidly set up in them, in which the fine nerve-tubule melts away, the axis-cylinder is broken across, the medullary matter escapes in the form of oilgivbules, and the whole mass of nerve becomes disintegrated, and subject to soft atrophic changes. Then restorative changes follow in the living nerve.

Let me mention an experiment in reference to the idea of compression only. There is no doubt, it appears that these bundles must be compressed. The canals in which they lie are smaller, the lymphatic space round about them is diminished, and the bundles look as if they were compressed; and no doubt they are subject to extreme lateral tension. But it occurred to me to ask, What happens when you elongate a tube? The channels are, of course, tubes. So, again, the medullary sheath of a nerve is but a hollow tube containing material. What happens when a tube is elongated? Is its original cubic capacity increased or diminished? You will probably think neither the one nor the other--that is, in fact, what I. supposed. But a very simple experiment will show that, in an elastic tube, if $I$ extend it, its capacity is increased. Here is some fluid in a glass tube ending in a piece of elastic tube below; if $I$ pull that down, you will see that the fluid descends. Here, then, is an actual proof that, given an elastic tube of a certain length and elongating it, its capacity is greater than in the unstretched condition. If you apply this to what might happen in the nerve, you find that the perineurial channels, although diminished in transverse diameter, are so much elongated in the act of stretching that their total capacity is increased and not diminished. And so with regard to the tubules; for I believe what is true on a large scale must be true on a small; these little tubules being elongated must really have a greater capacity than when they are in a natural condition. Now, if this be so, we can understand that this stretching may take place without much compression. It is a subject for further investigation, I believe, and I would not pronounce a positive opinion upon it; and $I$ have no time for physiological research. But I can see that here is a sort of struggle between two forces; on the one hand, there is the compression, and there is the expansion; there is the narrowing of the tube. and there is the stretching out of its contents to fill the tube which contains more space; and the result, we can easily see, would be such as to shatter up-to use the phrase-the medullary sheath irito fragments, and produce the temporary destruction which we sec represented in these diagrams.

Now, as to the physiological results of nerve-stretching, that is, on the functions and properties of the nerve. Here we find, also, an endless variety of statement and opinion; but, speaking generally, it may be said that all the functions of a nerve are influenced by its being drawn out or stretchecl in a greater or less degree, according to the amount of force. The motor properties and the sensory propertics are both of them diminished. If the stretching be of a sufficient degree at first, there is very little depression; but, if the stretching be made stronger and stronger, the motor and sensory functions are depressed. The motor functions are less markedly depressed than the sensory functions. All the sensory functions are depressed, not only that of common touch, but the sense of temperature, heat and cold, the sense of pressure, are all diminished, providing the stretching be strong enough. That, of coursc, one would understand. Then, with regard to the irritability of the nerve, that is, its power of conducting impressions-this has been tested in various ways; and it is shown that, whon a nerve is stretched slightly, its irritability is increased. This is a very important element, I think, in our attcmpts to cxplain what happens in the operation of nerve-stretching. The irritability of the nerve is increased; but, if you go on with the extension, the irritability gradually diminishes, and is finally extinguished. That early increase of the irritability of the nerve seems to be an important factor in attempting to explain the way in which this operation acts upon living nerves.

Now, with regard to the reflcx properties of a nerve: they also are of necessity gradually diminished: but, curiously enough, they are not so suddenly affected as the voluntary motor or the sensory function; and here we have, perhaps, an explanation in the fact that I mentioned, that moderate degrees of pressure, and even tolerably strong pressure, serve to raise the irritability of a nerve and not to diminish it. It is only when it goes beyond a certain point that it is diminished. In reference to this reflex action not being extinguished so early as sensation and motion. we shall obtain, perhaps, a certain clue to the modus operandi of nerve-stretching in the cure of pain. These researches do not, by any means, exhaust what we ought to say concerning the action of nerve-stretching upon the functions of the nerve; for here, in a most important momoir by Stintzing, which it is scarcely possible to praise too much, we have the first most elaborate inquiry, on physiological grounds, as to the effects of nerve-stretching upon the functions of the nerves. He has gone over the whole question, and proved, to : great extent, what was known before. But the important part about his inquiry is this, that he measured every result; he measures the touch by an asthesiometer; he measrues the cutaneous sensibility by the faradaic current, and the muscular power by the constant current. He puts the results into curves, so that the facts are recorded in a ranner which can immediately be understood and appreciated in a much more thorough way than they had ever been before. Again, he has compared the effects produced by using different weights, often using proportionate weights to the weight of the animal's body experimented upon; so that he gives us an account of the effect of the weight of half the animal's body on the sciatic nerve, of $\frac{3}{10}, \frac{4}{15}, \frac{5}{10}$, working up to 1.8 , which I mentioned to you as one of his figures, showing the physiological effect of various degrees of stretching. Setting aside all the irregularities of earlier experimenters, who trusted to merely describing that they stretched the nerve and watched the result, but gave no idea how much force was applied, - he measures the force and measures the effect. Besides this, he has also compared the effect of stretching on the one side as compared with what happens on the other side; and, in this way, he bas shown that the effect of stretching nerves on the one side, passes over, in various degrees, to the opposite side of the nervous system; an important factor, in regard to any explanation which may be attempted of the mode in which nerve-stretching cures disease. And in other ways he has compared the effects of stretching different nerves, as the sciatic and the crural; he has stretched nerves upwards and downwards; and he has pushed his inquiries, tabulated and measured his results, so that his is certainly the most trustworthy account of the effects produced-upon the functions of nerves by nerve-stretching that we yet possess; and, no doubt, it will ultinately lead to modifications of opinion.

Now, amongst the interesting inquiries that have been made as to the effect of nerve-stretching, there comes this. Are the mechanical effects of nerve-pulling transmitted on to the spinal cord, or are they not? Now here, Vogt, one of the earlier observers, said not. Gillette, a French observer, says, Yes-if you stretched the sciatic nerve, you moved the spinal cord in the spinal canal. More recent observers have also come, apparently, to the same conclusion. Cuussenbauer and Braun, working together, have recorded that they have seen, in one case, a movement 
through the whole length of the cord, up to th: occipital foramen. In another case, the movement was not measu:able, and, in a third case, they saw no movement at all. Now, in the case in which the movement was measured, one record which, when you take it in millimetres, looks large, turns out to be one-fiftieth of an inch. In this one case, the greatest amount of movement, in the lumbar region, amounts to one-tenth of an inch; of course, this is a palpable movement. Now, this positive observation is made by the same observers, who, in one of their cases, recognise hardly any movement, and in another they recognise none at all. Dana, an American observer, confirms the fact of there being some movement; Symington doubts it. Langenbuch, one of the greatest authorities on nerve-stretching, who has stretched more nerves than any living man, tried this, and he found exactly what was met with in one of Gussenbauer and Braun's cases: that, although the movement was propagated to the spinal ganglia and to the sheaths that cover the roots of the spinal nerves, as they pass out of the intravertebral foramina, it was not communicated to the intraspinal roots of the nerves, and necessarily not communicated to the cord. Mr. Horsley has inquired into this point in four experiments upon the sciatica in the dead body, and he found no movement; and, yesterday, having the opportunity again of testing the point in this College, together with Mr. Horsley, I repeated this experiment, and we found no movement. We did find what may be an explanation of an apparent movement in certain cases; we found that, with the greatest care, the spinal column, when you apply traction to the nerves, has its curves a little modified; so that, in fact, what forms a series of gentle curves becomes straighter in some parts, and that, of course, produces a movement in the cord. When that was prevented, we had no movement. We recognised a movement in the dura mater; and, if you remember the attachment of the ligamentum denticulatum on either side, between the dura mater and the cord, you will see that, if you move the dura mater, you can gently disturb the cord. I believe, in these two ways, such casual movements as have been observed by Braun, and Gussenbauer, and Dana, may be fully accounted for; and that, practically, there is no stretching mechanical effect propagated through the roots of the nerves to the spinal cord. We find the stretching effect pass to the sciatic plexus; we find it passing to the roots of the nerves, where it must disturb the spinal ganglia on the posterior roots, and it must disturb the dura mater. It may, by disturbing the dura mater, shake the cord a little through the ligamentum denticulatum on either side; but we find no change of tension in the intra-spinal, or intra-meningeal part of the nerve, and no movement in the cord.

Here, therefore, we get another important factor when we attempt to explain the modus operandi of stretching nerves in the cure of disease.

These are the chief points which I wish to direct your attention to, in reference to the actual effects of stretching nerves. But now let us ask ourselves what are the therapeutical effects; and on this part of the subject I must dwell very briefly, knowing that you all have access to the medical periodicals, and that some have tested for themselves the success or failure of these operations. I content myself, therefore, with pointing out to you a Table constructed from one published br Artaud and Gilson, and added to by Ceccherelli, who has written a most interesting review on this subject in the Italian journal Lo Sperimentale-very important, and travelling very much on the sdme lines, only therapeutically, as Stintzing has

Results of 252 Cases of Nerve-Stretching in Disease.-(Artaud and Gilson, with Ceccherelli.)

\begin{tabular}{|c|c|c|c|c|c|c|}
\hline & 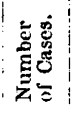 & 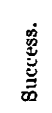 & 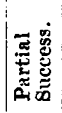 & 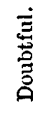 & 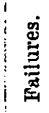 & 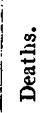 \\
\hline euralgia of all kinds & $\Leftrightarrow$ & it & 12 & 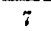 & (;) & - \\
\hline & 317 & & 16 & & $\approx$ & 8 \\
\hline Central disease with contractions.. & 14 & 12 & 1 & - & 1 & - \\
\hline 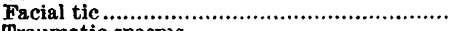 & 7 & 6 & - & - & 1 & - \\
\hline 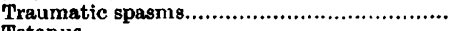 & 12 & 10 & 1 & - & 1 & $\overline{0}$ \\
\hline 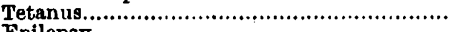 & 45 & 14 & - & 2 & - & 29 \\
\hline $\begin{array}{l}\text { Epilepsy } \\
\text { Peripheral paralysis (motor and sensort)... }\end{array}$ & 34 & $\begin{array}{c}1 \\
34\end{array}$ & 3 & $=$ & $\bar{z}$ & 二 \\
\hline Lepra (included in the above) ..................................... & - & - & - & - & - & - \\
\hline Optic nerve (Hallucinations) ......................... & 1 & - & - & 1 & - & - \\
\hline Totais....................... & 252 & 156 & 33 & 10 & 16 & 37 \\
\hline
\end{tabular}

done by practical observation. Ceccherelli's figures, added to Artaud and Gilson's, give us this enormous list of two hundred and fifty-two cases of nerve-stretching in various diseases. If you look at certain of these several columns, you will find, no doubt, that the successes are comparatively few. Take, for example, tetanus and epilepsy, the successes are but few; but on referring to the Table we must observe the two upper components of the Table, namely, the diseases classified under the term "neuralgia" and the special spinal disease which produces locomotor ataxy and sclerosis of the posterior columns of the cord and the posterior nerve-roots. These are the two diseases that are chiefly responsible for what I should call pain - the "pain" which is the subject of consideration of this lecture: neuralgia, with all its proJonged torture; and tabes or locomotor ataxy, with its lightning-flashes. How is it with regard to those? Now, with regard to neuralgia, you see the proportion of successes in the first column is enormous. With regard to tabes, the successes are far fewer; but the partial improvements, in which a modification and amelioration, or only a temporary cessation, of pain is mentioned, are also not to be ignored. The success in actual neuralgia is great; the success in curing the pain of tabes is much less; still the pains are improved, and that is at least one part of my subject which I wish to bring before you to-day. I could add to that Table many successes and many failures from other sources. I will caution you against accepting its details ; we all know that statistics must be received with distrust. We all know that there are cases of failure here unrecorded; and that it is extremely difficult to analyse and describe the subjective condition of pain. We know, also, that patients often describe their symptoms too hopefully; and the surgeon is only too glad to receive such accounts; we know, lastly, that many recurrences must pass utterly unnoticed in these Tables; that a case is put down as a success which, if watched sufficiently long, would not justify that term. Making full allowance for all this, still you will find such a preponderance of facts in favour of nerve-stretching curing neuralgia, that rou cannot dispute the fact that it often does and will cure that disease.

Further, this Table from Nocht, constructed long after the other in reference to the operation of nerve-stretching in tabes, gives us, certainly, sufficient encouragement to believe that nerve-stretching is not only available for the cure of neuralgia, but also for the Results of Nerve-Strctching (Nocht).

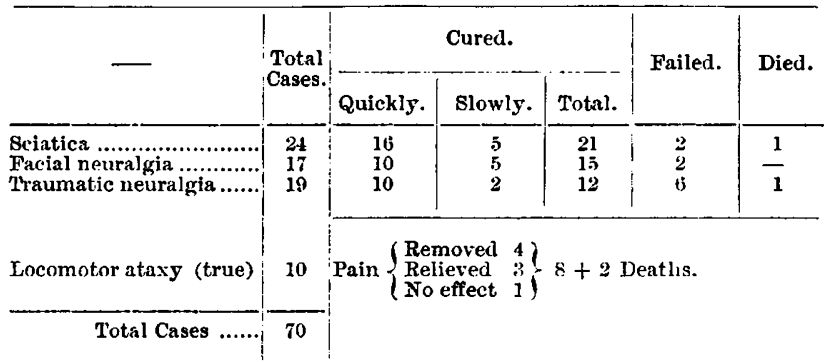

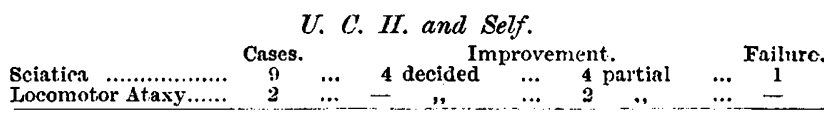

amelioration of tabes. Time will not permit me to analyse these figures fully ; but I may say in reference to them, and to any other points which may require amplification, that I shall, of course, if this lecture be considered worthy of publication, feel bound to explain them. I desire to state now that the Tables contain most of the British cases.

I may pass on, therefore, with a regret that I have no more time to dwell on this part of the subject--to consider the possible modes in which nerve-stretching cures the pains of neuralgia and tabes ; and to these two points I must exclusively confine mF attention. With regard to the pain of ncuralgia, it has such peculiar characters, that we can separate it altogether from the pain produced by tabes. First of all, it is commonly unilateral; that of tabes is liable to fly from side to side. The pain of neuralgia runs along the course of a nerve. It is concentrated, as it were, along the path or territory of a particular nerve. The pain of locomotor ataxy, on the other hand, is diffused over the areas of many nerves ; it may be on both sides of the body, it may be in the two limbs, or in the trunk; in fact, you do not know where it may not be.

Again, the pain of neuralgia is always increased by movement or pressure, and this gives it, of course, a local character. 
The pain of neuralgia, also, is more severe at certain apertures where the nerves pass out of the osseous or fibrous framework of the body, or pass round given points of bone. These, for instance, are painful points. The painful point of sciatica is where the nerve passes out close to the sacro-sciatic ligament, and every movement or twitching of the adjacent muscles is liable to press upon a tender nerve, and also to influence its circulation by acting on the branches of the sciatic artery and vein which supply the nerve. Another painful point is just below the head of the fibula, where the external popliteal turns round below the head of that bone, is there bound down by the fascia, and is liable to pressure. The fact, indeed, is that neuralgic pains are increased not only by external pressure and by internal movement, but they manifest themselves at particular points of the nerve, which, owing to the construction of the body, are themselves liable to internal pressure, including pressure upon their blood-vessels, and thus to a hindrance to their circulation, and an intensification of any hyperremia to which they may be subjected.
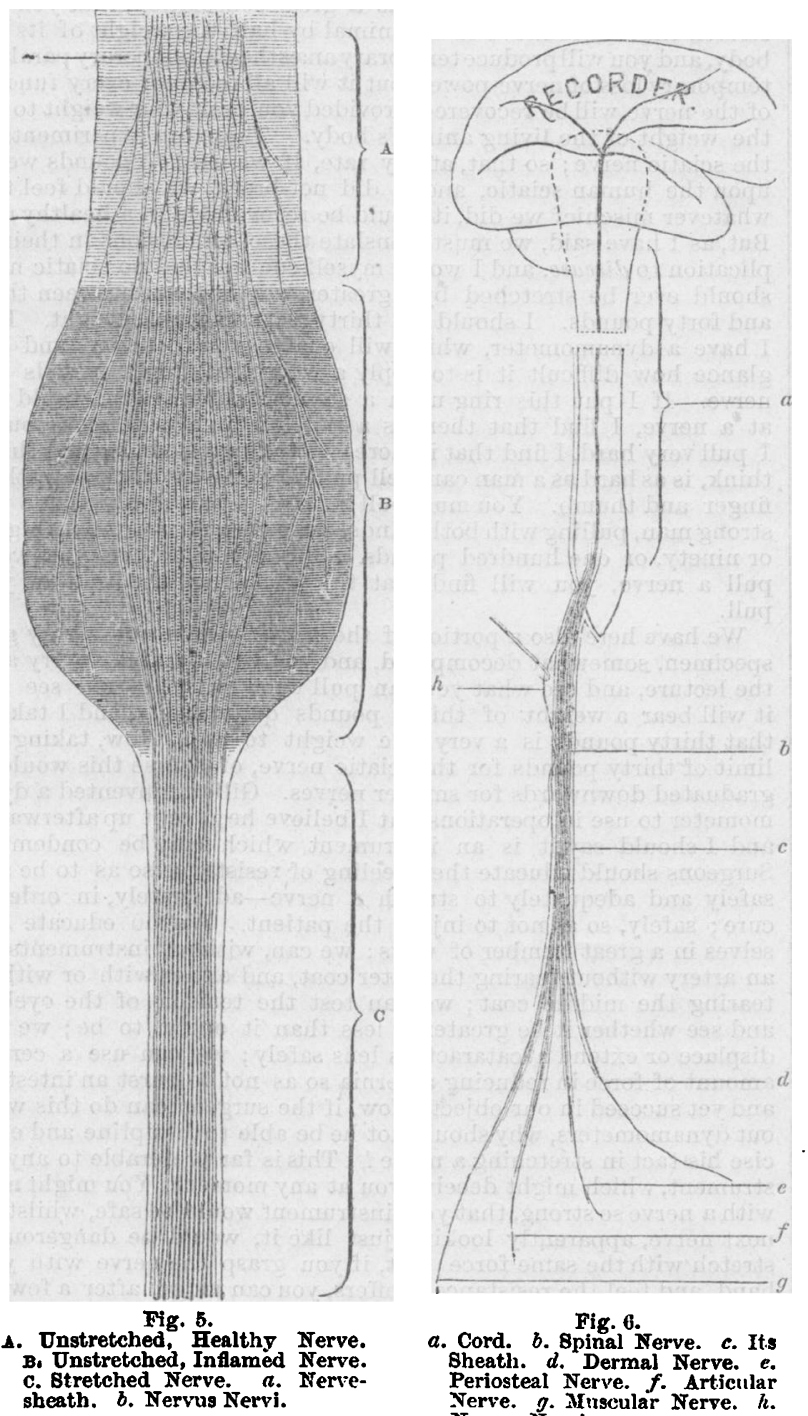

Fig. 6.

a. Cord. b. Spinal Nerve, c. Its Sheath. $d$. Dermal Nerve. $e$. Periosteal Nerve. $f$. Articular Nerve. g. Muscular Nerve. $h$ Nervus Nervi.

I would also venture to point out that we must consider neuralgia, I think at any rate in some cases, as not a pain in the nerve-tubules (otherwise it surely would be transferred by the consciousness to the extremities of those nerve-fibres), but as a pain in the nerve itself; and this, I think, points out that it must be pain due to what I have ventured to call the nervi nervorum. Sappey has described such nervi nervorum ranining on to the optic nerve only, in that case, of course, supplied by the ciliary nerves. I think, on the other hand, we may see that, in an ordinary sensory nerve, or a mixed sensory and motor nerve, the fibres which supply the epineurium and the perineurium probably come from the nerve itself. This has not yet been demonstrated in the ordinary nerves, but I hope that someone will take up the point and will succeed in doing so. I have imagined them to exist, and in the upper part of this diagram (Fig. 5), in a healthy nerve, you will see the so-called nervi nervorum supposed to be coming out from the trunk of the nerve, and ramifying in its sheath; they ramify in other fibrous tissues, and it is the nerves alone in such tissues that produce pain. We speak of neuralgic pain, as if there was something peculiar and striking in it. So there is, seeing that it is pain in the nerve; but all pain is in nerves. The periosteum does not feel pain except through its nerves. So with the skin, muscles, and tendons-nothing feels pain except through its own nerves. And here, I contend, the argument is strong in favour of the idea that there are really these nervi nervorum in the sheath of a nerve. If you touch a dermal nerve (Fig. 6), the sense of pain is carried up to the recorder, that is, it is received on the spinal cord, and is carried up to the brain, and produces a sensation of pain at the skin-point corresponding to it. So with the periosteal sensory nerve, so with the nerve going to a joint, so with the nerve going to muscle ancl tendon, and so with the neural nerve, if I may so call it-the nervus nervi-coming out from the sheath of the nerve, which produces a sense of pain upon its own extremity. Now, supposing this to be the case, and that we have the nerve stretched, what can become of these nervi nervorum? In an inflamed state, represented by the swollen part of the nerve, the hypericmic condition, the plastic matter thrown out, the irritating fluids, gouty, rheumatic, etc., must excite these nerves. The lower part of the diagram represents the proportionate effect of stretching as compared with the upper part. Now what, in that case, must become of the proper nervi vervorum? They must be stretched, they must be broken; their tubuli must be actually sacrificed, in this way, very much more completely than the tubuli of the nerve in the interior. These are soft and elastic and free to move, and we find they become very elongated; but they do not become broken, except in rare instances. But what must happen to nerve tubuli, the extremities of which are fastened into the sheath ? They must be stretched so as to be paralysed completely; and, in this way, I believe we can account for the relief of certain neuralgic pains. Of course, we must not ignore the fact that, side by side with these neurilemmal or perineural conditions, there are concitions which will cause pain in the internal tubules themselves, and these are probably arrested or interrupted by the shattering of the medullary tissue and the stretching of the axis-cylinder, which I have described as actually taking place. I would not for a moment suppose that all neuralgiæ are due to nervi nervorum, but I do think that a large proportion are. They may be considered to be true peripheral neuralgire. Nerve-stretching probably acts in the way I have described in a great many cases, but, in other cases, by partially benumbing or paralysing the internal tubules, arresting their functions for a time : or, further, by indirect effects on nerve centres.

With regard to tabes-pains, they are produced evidently in association, not so much with changes in the nerves outside the dura mater, but rather, so far as we know, with changes in the posterior roots, and in the spinal cord. Still, observe, the changes are chiefly in conductors; they are not in the grey substance alone; they are rather disproportionately in the conductors, that is, in the roots of the nerves and in the posterior columns; and, although we speak of this tabes-affection as a central affection, I think we should take care to eliminate from our minds the idea that it is entircly a greymatter disease, or rather, we should not overlook the fact that it still is a disease of the conductors of nervous impressions rather than of the receiver of nervous impressions. Certainly the conductor suffers obviously more than the receiver, although the receiver, no doubt, likewise undergoes changes; the grey matter undergoes changes, but the white matter is more conspicuously affected.

But how can nerve-stretching affect these intra-meningeal, these intra-dura-matral conditions? We must have recourse to something differcnt from the mere mechanical effect of stretching, because we have shown that stretching does not go beyond the roots of the nerves in the sheaths of the dura mater. But there it affects the ganglia, there it produces an excitation of the vasi-motor centres, or trophic centres; and, to the reaction that takes place, and the changes induced in the nerve-elements in consequence of that, 1 think we 
manst look for the benefit obtained in cases of tabes rlorsalis or locomotor ataxy.

The explanation of the cure of neuralgia seems to be easy when it is peripher:tl. Admitting that there are other neuralgix which are central, the effect of nerve-stretching in the cure of those must be by producing some indirect effect upon central nerve-elements through trophic changes, probably induced by the disturbance of vaso-motor actions. Here, again, I must ask you to excuse me from following out these ideas to their fullest extent; the scope of my lecture being rather to illustrate here and there points in the subject which sen to me to be most interesting, leaving it to others who are also engaged in the practice of our profession, and in the investigation of disease, to follow out any hint which I may have dropped.

I pursue my comrse, therefore, by asking what are the cases in which ncree-styctching should be cmployerl, and what seem to be the indications for the proper morle of employing it. Now, it seems quite certain that, in these preparations on the table, we have cases in which nerve-stretching is suitable. Here are two examples of neuromata of stumps. This is a painfnl ulcer of the skin, for which, in fomer days, a limb was sacrificed, and it might probably have been curcel by stretching the posterior tibial nerve, or what ever nerve was involved. This again, is a nerve which has received some damage, but only appears to have on it a mass of coagulated blood, still calsing immense suffering, but quite probably curable by nerve-stretching. Here is another case of a painful ulcer which might, I tinink, have been well treated by nerve-stretching. In this jar we have a beautiful example of nerve-thickening of the median and ulnar nerves, opposite the annular ligament of the wrist, causing such excruciatincr pain that the forearm was amputated. This wa a case which, I irmly believe, would have been completely cured by nerve-stretching for neuralgic peripheral disease.

This, again, is a case which illustrates the contrary view; it is the fracturel limb of a donkey, with a nerve entangled in the cicatrix or in the soft callus. Here, probably, the treatment would be, not norre-stretching, but dissecting up the nerve, restoring it to its freedom, if possible, or, if not, paring off the ends of the nerve and ligaturing them together, as has been done with success by one of our own Council, at jresent, in this room. Then, there are tumours of nerves in which one could not recommend this operation-multiple neuromata situated in the very heart or substance of a nerve. In such cases, stretching would certaiuly be useless. In cases like that, onc would dissect out the tumour; or, if not, one must sacrifice the nerve.

Then we get still more formidable examples of tumours of nerves, in which cases tumours exist more or less in nerves in every part of the body. Here is a sciatic nerve in which there are at least a dozen or fifteen little nodules. Here, again, is a specimen of an arm in which every nerve has one or two nodules upon it. These multiple neuromas are, some cancerous, some soft sarcomas, and others fibromas; but all cascs of this kind would be utterly unsuitable for nerve-stretching. Here is a beautiful specimen of a tumour pressing on the intra-spinal sensory roots of lumbar nerves, in which the most excruciating agony was suffered. In that case, I, some years ago, divilled as maly of the branches of the crural nerve as I could get at, without relicf. After death, the patient being examined, a tumour was found inside the spinal canal, sufficiently explaining the reason of the failure of the operation to give relief.

Could we hope to get any benefit in such a case from nervestretching? The probability, I am afraid, is not; because we have shown that nerve-stretching does not pass beyond the dura mater, docs not affect the posterior roots. Besides, no change in the nutrition of the tumour, tinrough the vasomotor action, could be expected to give relief, as it seems to be able to give relief in cases of tabes dorsalis.

Finally, as to the mode in which this new operation should be set about. First of all, we may indulge in a generalisation with regard to the physical experiments, investigations into anatomical stracture, and how that is altered by stretching, those on the functional disturbances that take place in nerves, and, lastly, the observations on the therapentic effects of stretching nerves-all of which I have been able to glance at, viz., that we should setvery little value on these if they did not furnish us guides for the mode of operating so far as we are at present able to use them safely. I need not say, with regard to these operations, that they must be directed to the nerve itself; that is to say, that in all cases of neuralgia (with one exception, which $I$ shall mention presently) the operation consists in exposing the nerve, lifting it either with a hook or with the finger, stretching it to a certain point so as to produce that palpable stretching of which I have spoken, and without which the operation will fail.

To what extent may we stretch? These Tables do not give us any reliable information if we translate them literally, because if you take the mean of these numbers that will be an unsafe guide. There have been sciatic nerves broken, as you see, at 82 , whereas the nean is $185 \mathrm{lbs}$. Therefore, the arithmetical mean is of no value at all ; every practical surgeon would shake his head and shudder, or laugh at it. Nor can you take the lowest of these numbers, 82 , because some sciatic nerves may break at a lower weight than that.

Stintzing's obscrvations have shown that, in the living nerve, you may safely stretch it with half the weight of the animal's borly. Here we get a little safer guide that will diminish the st rain or force on the sciatic nerve from 80 pounds, to half the average weight of a man, or 75 pounds. But that is not a perfectly safe guide, becanse we are dealing with diseased nerves. The nerve on which we are operating is not $\mathrm{a}$ healthy nerve, the man not a healt hy man; you must go, therefore, far below that limit. Stint/ing has observed this, however, which is a great consolation, that you may stretch the sciatic nerve of an animal by half the weight of its own body, and you will produce temporary anæesthesia, temporary paralysis, temporary loss of nerve-power, but it will all recover; every function of the nerve will be recovered, provided you limit your weight to half the weight of the living animal's body. These are experiments on the sciatic nerve; so that, at any rate, if we used 75 pounds weight upon the human sciatic, and it did not break, we should fecl that, whatever mischief we did, it would be recoverable in a healthy man. But, as I have said, we must translate these conclusions in their application to disease, and I would myself counsel that no sciatic nerve should ever he stretched by a greater weight than between thirty and forty pounds. I should say thirty is a reasonable weight. Here I have a dynamometer, which will enable you to understand at a glance how diflicult it is to apply a weight of thirty pounds to a nerve. If $I$ put this ring upon a staple and pull, as I would pull at a nerve, 1 find that there is a pull of twenty pounds; but if I pull very hard, I find that it increases to thirty pounds, and that, I think, is as hard as a man can well pull, holding a soft nerve with hi. finger and thumb. You must pull gently. You will find that a very strong man, pulling with both hands, can only pull up to about eiglity, or ninety, or one hundred pounds. But if you pull as you would pull a nerve, you will find that thirty is about the limit of your pull.

We have here also a portion of the sciatic nerve, not a very good specimen, somewhat decomposed, and you will be able to try after the lecture, and see what you can pull upon it. You will see how it will bear a weight of thirty pounds quite easily, and I take it that thirty pounds is a very safe weight to use. Now, taking the limit of thirty pounds for the sciatic nerve, of course this would be graduated downwards for smaller nerves. Gillette invented a dynamometer to use in operations, but $I$ believe he gave it up afterwards and I should say it is an instrument which may be condemned, Surgeons should educate their feeling of resistance so as to be able safely and adequately to stretch a nerve-adequately, in order to cure; safely, so as not to injure the patient. We do educate ourselves in a great number of ways : we can, without instruments, tic an artery without tearing the outer coat, and either with or without tearing the middle coat; we can test the tension of the cyeball. and see whether it be greater or less than it ought to be; we can displace or extend a cataractous lens safely; we can use a certain amount of force in reducing a hernia so as not to burst an intestine, and set succeed in our object. Now, if the surgeon can do this without dynamometers, why should not he be able to discipline and exer. cise his tact in stretching a nerve ? This is far preferable to any instrument, which might deceive you at any moment. You might meet with a nerve so strong, that your instrument would be safe, whilst the next nerve, apparently looking just like it, would be dangerous to stretch with the same force; but, if you grasp the nerve with your hand, and feel the resistance it offers, yon can judge, after a few experiments on a dead nerve, how much force is necessary to produce that adequate stretching of which I have spoken; the nerve sensibly yields to your traction, you feel an internal creeping movement in the particles of the nerve-of the sheath, no doubt-you feel a certain attrition and vibration going on, and you must edlucate yourself to that, and then you will be safe.

But, now, there are two other points of great importance in nervestretching which, I think, have not received sufticient attention; and that is, not the direction, but the mode, in which you pull, either with irregular jerks, or with a steady pull, and hon long that pull should last. Here, again, Stintring comes in to our aid inci- 
dentally. You can make use of his facts in this and many other ways. Thus he found the best way to produce his results with measured weights, and the only way to make his experiments parallel, was to keep up the pressure or the weight for a certain uniform time. Now, the time that he adopted in various experiments was from three to six minutes; but, in certain experiments, where he wished to have exactly parallel resalts, he kept up the stretching uniformly for five minutes. I believe if stretching with a moderate power, prolonged for a certain time, was really the modus operandi adopted by Surgeons, they would have better and safer results than they have now. A sudden pull is not enough, however hard it may be; a series of jerks, also, are inadequate, for each jerk only repeats the mischief of the impression produced by the previous one; but, if you put a strain upon the nerve, and stretch continuously, say for five minutes, with a moderate pull, you are producing insensibly those internal changes of which $I$ have spoken as essential to the production of genuine nerve-stretching. Now, with regard to pulling the nerves upwards or downwards, it does not seem, in experiments, to have had much effect. Stintzing says that, on therapeutic grounds, it would be far better to stretch downwards in tabes, and upivards in neuralgia. . I should say myself, stretch both ways for neuralgia, and yet as near to the seat of severest pain as possible. It is of less consequence to stretch from the extremities in tabes; it is essential to stretch from the trunk or body.

Before concluding, I must ask you to bear in mind that the catting operation to which $I$ have alluded hitherto is not the only way of stretching nerves; for it has been found, in the case of the sciatic, that if you bend the thigh upon the body so that the knee comes op to the chin, and then straighten the leg upon the thigh, and flex the foot upon the leg, so as to stretch the ankle-joint also, you can produce an extraordinafy strain and tension upon the sciatic nerve as it passes out of the pelvis. Trombetta, who is a great advocate for this method-Billroth has the credit for introdncing it, but $I$ believe Trombetta was earlier-found that the sciatic nerve in the dead body could be stretched one inch by this proceeding; but the proceeding must be tolerably firm and resolute; and I would say, in order that it should succeed, it should be continued for five minutes. That is the sort of rule I would lay down in all these cases. $\mathrm{Mr}$. Horsley has stretched the sciatic nerve on the dead body in this way, and has found that it does diminish the diameter of the nerve. He intended to have brought the specimen here to compare it with an unstretched nerve. As a matter of fact, the nerve is stretched according to Trombetta, and it is diminished in diameter according to Horsley. In a living person, I have found the exposed sciatic to be very tightly stretched by forced flexion of the lower limb. Here there is an undoubted power of stretching the sciatic without a cutting operation; and the results of this, which the Germans call the unblutige operation, as contrasted with the blutige operation, are very satisfactory, as shown by Lange, Trombetta, and Stintzing who adds a clinical chapter after his experimental results. It is there stated that this method of stretching the sciatic for tabes dorsalis, in four cases, turned out admirably in one, produced decided improvement in the second, partial improvement in the third, and a little less improvement in the fourth: so that, in fact, there are means of stretching sciatic nerves successfully without the cutting operation. Again, quite recently, I lit upon some observations made by Motsckutkowski with reference to what happens in the use of Sayre's apparatus for suspending the body. The body is said to be elongated from an inch to two inches and a quarter-that is, the entire body; but he found that the trunk is elongated to nearly seven-eighths of an inch. He opened the spinal canal, and then suspended the body in the same way, and he found the spine itself was elongated seven-eighths of an inch; but he found, as confirmatory of what I have already told you, that, although the membranes moved, and he thought there was a slight amount of tension on the posterior roots of the nerves, he was not quite sure of that, and at all events it was a very slight degree of tension. But, suppose there was a degree of tension, consider the amount of stretching that he was now employing, stretching which was acting on every part of the vertebral column, not limited to the sacrolumbar part alone; and it is just possible in this way, by stretching the entire vertebral column, and undoing its curves, he did get a certain amount of tension on the posterior roots of the nerves, and therefore on the cord. His practical application of this consisted in suspending the patients suffering from locomotor ataxy, for ten minutes at a time, three times a week. He reports fifteen cases. In thirteen cases, there was positive diminution of the pains; as well as of the abnormal sensations which characterise that painful disease; some decided improvement in the ataxic condition, and general recovery of muscular power. In thirteen cases, withoc.t going into detail, this method of stretching nerves has succeeded in relieving those agonizing pains of tabes or locomotor ataxy, with which we are concerned here. In two cases, it produced either no result or a very unobservable result.

With regard to the dangers of nerve-stretching in tabes, if you read the cases, you will find that they are comparatively few. One patient died from chloroform, another from thrombosis in the veins, another from pyrmia due to inattention to antiseptic dressings, a fourth from a similar cause. Then wo may record three or four cases in which, undoubtedly, the death may be attributed to disease of the spinal cord set up by nerve-stretching, but one of these was a case of spasmodic disease. These mishaps have taken place in other operations. A boy. had his lips and knees contracted; he had these stretched; he had collapse, and died in two or three days. Hæmorrhages were found along the cord. Shampooing, even, has been found to result in a fatal issuc--no doubt, from an imperfect mocle of performing it. If, therefore, I conclude by saying that ncrre-stretching demands much further consideration, and that the facts already bronght to light upon this subject serve to illustrate more clearly the mode in which it acts, and indicate that there should be one mode of treatment for neuralgia and another mode for tabes, I trust we may hope that in future this operation will takeits place more prominently in English surgery.

I will conelude by thanking Mr. Horsley for his very great assist. ance; also my old house-surgeon, Mr. Thring, for collecting the University College Hospital cases for me; and Mr. Castañeda for his great trouble in verifying the tabulated cases. I again repeat that I should hope, if I publish this lecture, to furnish such appendices as will fill up gaps, which, for want of time, I have been compelled to leave open.

Once more assuming my position as Presiclent of this College, I beg to thank you most sincerely for your attendance here to-lay, and to express my obligations to the Members, Fellows, ancl Counci for the honour they have done me; and also to say, with regard to our visitors, that ther have, undonbtedly, by their presence contributed to our attempt to pay a just tribute to the memory of the lady who founded these lectures, and also to keep alive the recollection of the physician in whose honour they have been foundea.

Heslti of Foreign Cities. - It appears, from statistics pablished in the Registrar-General's return for the week ending the 8th instant, that the death-rate was recently equal to 21.9 per 1000 in Bombay, and 36.1 in Madras. Small-pox caused 34 deaths in Madras, where "fever" fatality was also considerably greater than in Bombay. According to the most recent weekly returns, the average annual death-rate in twenty-two of the largest European cities was equal to 24.3 of their aggregate population; this rate was 2.7 above the mean rate last week in the twenty-eight large English towns. The rate in St. Petersburg did not exceed 22.9, showing a further decline from the rates in recent weeks, although the 408 deaths in. cluded 28 fatal cases of diphtheria. In three other northern cities -Copenhagen, Stockholm, and Christiania - the mean death-rate was only 19.3, the highest rate being 25.2 in Stockholm, where the 88 deaths included 8 from diphtheria and croup, and 6 from scarlet fever. In Paris, the rate was 22.6, and the deaths incluted 43 from diphtheria and croup, and 32 from typhoid fever. 'The 183 deaths in Brussels, of which 8 were fatal cases of small-pox, were equal to a rate of 22.8. In Geneva, the 31 deaths gave a rate of 23.1. In the three principal Dutch cities-Amsterdam, Rotterdam, and the Hague-the rates ranged from 18.8 in the Hague to 27.0 in $\mathbf{A m}$ sterdam, the mean rate in the three towns being 25.1; in Amsterdam, 26 deaths were referred to croup, and 12 to mcasles. The Registrar-General's table includes eight German and Austrian cities, in which the death-rate areraged 25.8 , and ranged from 21.1 and 21.9 in Hamburg and Buda-Pesth, to 30.1 in Munich and 32.1 in Prague. Small-pox caused 24 deaths in Praque, and diphtheria 80 in Berlin and 26 in Dresden; measles showed fatal prevalence in Hamburg, Vienna, and Munich. The rate was equal to 23.3 in Rome, 24.2 in Turin, and 28.2 in Venice, the mean in these three Italian cities being $24.6 ; 11$ deaths were referred to malarial fever in Rome and 8 and 6 deaths respectively to measles and typhoid fever in Turin. The 132 deaths in Lisbon, including 5 fatal cases of diphtheria, were equal to a rate of 32.9. In four of the principal American oities, the mean death-rate was 20.9 ; the lowest rate was 17.9 in Brooklyn, and the highest (22.4) in New York. Typhoid fever caused 15 dcaths in New York, 12 in Philadelphia, and 7 in Balti more; diphtheria showed morc or less fatal prevalence in each of these American cities. 